\title{
Research on Stock Returns and Volatility-Based on ARCH - GARCH Model
}

\author{
Linna Hu \\ School of Economics, Shanghai University, P.R.China \\ 2361103055@qq.com
}

Keywords: Time series; Stock returns; Volatility; ARCH - GARCH Model

\begin{abstract}
The real estate industry occupies the important position and the role in the national economy system and China's securities market. This paper collects time series data for real estate stocks [1].Firstly, establish a reasonable ARMA model to predict and analyze the stock price. At the same time, in order to prevent the uncertainty and risk of the stock market, and measure the volatility of the stock yield effectively, and the reasonable GARCH model is established to study the volatility of the stock return rate. Finally, the analysis of the yield and volatility of the established model stock is of practical significance to the future trend of stock price forecast and the development of investment strategy [2], which can provide reliable information service and decision guidance for investors and decision makers.
\end{abstract}

\section{Introduction}

China's real estate industry occupies a pivotal position in the national economy. It is an important industry of the national economy, real estate listed companies, through the study of stock prices can understand their own business situation, the future business trend is also very strong Reference value; for the majority of investors, it is directly related to the confidence of the company's investment, and affect its further investment behavior; and the relevant state government departments, real estate listed company stock fluctuations can reflect the right The introduction of the corresponding real estate policies arising from the social and economic impact of the future development of policies to regulate the real estate market has a good reference value. Therefore, the analysis of real estate listed companies stock price movements and fluctuations is very necessary [3].

\section{Identification and Establishment of Simple Rate of Return Model}

This paper mainly selected the closing price of City Investment Holdings from January 4, 2005 to December 26, 2016, a total of 2911 samples. Empirical analysis uses EViews software [4]. Let $P_{t}$ be the closing price for the th trading day of Chengtou Holdings Company Limited, so that $\mathrm{r}=\ln \frac{\mathrm{P}_{\mathrm{t}}}{\mathrm{P}_{\mathrm{t}-1}}$ represents the simple rate of return of the th trading day.

The autoregressive moving average (ARMA) model is a kind of time series model [5]. The model is expressed as follows:

$$
\mathrm{r}_{\mathrm{t}}=\emptyset_{0}+\sum_{\mathrm{i}=1}^{\mathrm{P}} \emptyset_{\mathrm{i}} \mathrm{r}_{\mathrm{t}-\mathrm{i}}+\mathrm{a}_{\mathrm{t}}-\sum_{\mathrm{i}=1}^{\mathrm{q}} \mathrm{Q}_{\mathrm{i}} \mathrm{a}_{\mathrm{t}-\mathrm{i}}
$$

where $\left\{a_{t}\right\}$ is a white noise sequence and $p$ and $q$ are nonnegative integers [6]. The ARMA model is a combination of AR model and MA model, which includes both autoregressive terms and sliding averages.

Through the test of each model, including the significance of each coefficient and whether the residual sequence is white noise test, the final model is ARMA (7,5).The output of the model is as follows: 
Table 1 The result of $\operatorname{ARMA}(7,5)$

\begin{tabular}{crrrr}
\hline Variable & \multicolumn{1}{c}{ Coefficient } & \multicolumn{1}{c}{ Std. Error } & \multicolumn{1}{c}{ t-Statistic } & \multicolumn{1}{c}{ Prob. } \\
\hline \hline AR (7) & 0.052133 & 0.016907 & 3.083525 & 0.0021 \\
AR (1) & 0.438073 & 0.140147 & 3.125824 & 0.0018 \\
MA(1) & -0.362332 & 0.145396 & -2.492031 & 0.0128 \\
MA(5) & -0.056385 & 0.017423 & -3.236186 & 0.0012 \\
\hline \hline
\end{tabular}

From the above table, we can see that the $\mathrm{P}$ value of each coefficient is less than 0.05 , indicating that the model is reasonable. And then test whether the residual sequence of model ARMA $(7,5)$ is white noise test, the result is as follows:

\begin{tabular}{|c|c|c|c|c|c|c|}
\hline Autocorrelation & Partial Correlation & & $A C$ & PAC & $a-s t a t$ & Prod \\
\hline$\frac{1}{2}$ & $\begin{array}{l}\$ \\
\vdots \\
\vdots\end{array}$ & $\begin{array}{r}1 \\
2 \\
3 \\
4 \\
5 \\
6 \\
7 \\
8 \\
19 \\
11 \\
12 \\
13 \\
14 \\
15 \\
16 \\
18 \\
19 \\
20 \\
21 \\
21 \\
23 \\
24 \\
24 \\
25 \\
27 \\
28 \\
28 \\
30\end{array}$ & 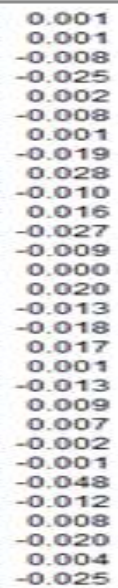 & 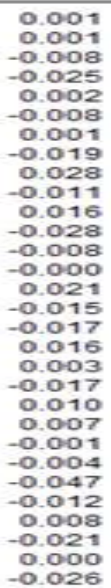 & 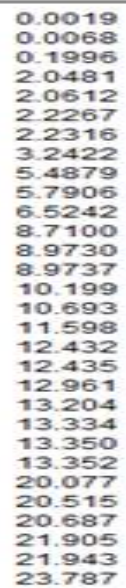 & 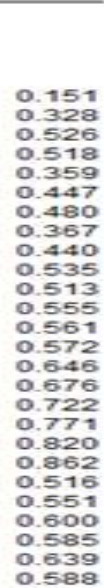 \\
\hline
\end{tabular}

Figure 1. The test of autocorrelation and partial autocorrelation of $\operatorname{ARMA}(7,5)$

From the above figure, we can see that the $\mathrm{p}$ value of each item is greater than 0.05 , so accept the null hypothesis, that there is no residual residual autocorrelation and the residual sequence is white noise sequence. It indicats that the model has extract all the information out. It can roughly simulate the original sequence, so the model is reasonable.

The final model is ARMA (7,5), and the specific expression of the ARMA $(7,5)$ model can be written entirely as follows using the R software [7]:

$$
\begin{gathered}
\mathrm{r}_{\mathrm{t}}=-0.058 \mathrm{r}_{\mathrm{t}-1}+0.4692 \mathrm{r}_{\mathrm{t}-2}-0.2823 \mathrm{r}_{\mathrm{t}-3}-0.1499 \mathrm{r}_{\mathrm{t}-4}-0.0213 \mathrm{r}_{\mathrm{t}-5}-0.0177 \mathrm{r}_{\mathrm{t}-6}+ \\
0.0647 \mathrm{r}_{\mathrm{t}-7}+0.1289 \varepsilon_{\mathrm{t}-1}-0.4317 \varepsilon_{\mathrm{t}-2}+0.2555 \varepsilon_{\mathrm{t}-3}+0.1363 \varepsilon_{\mathrm{t}-4}-0.0156 \varepsilon_{\mathrm{t}-5}+\varepsilon_{\mathrm{t}}
\end{gathered}
$$

where $\left\{r_{t}\right\}$ represents the simple yield sequence, $\left\{\varepsilon_{t}\right\}$ is the interference term.

\section{The Selection and Establishment of Volatility Model}

The GARCH model is a generalized ARCH model [8]. For the yield sequence for the yield sequence $\left\{\mathrm{r}_{\mathrm{t}}\right\}$, let $a_{t}=r_{t}-\mu_{t}$ be the new information at time t. Let $a_{t}$ obey the GARCH (m, s) model if $a_{t}$ satisfies the following formula:

$$
\mathrm{a}_{\mathrm{t}}=\sigma_{\mathrm{t}} \varepsilon_{\mathrm{t}}, \quad \sigma_{\mathrm{t}}^{2}=\alpha_{0}+\sum_{\mathrm{i}=1}^{\mathrm{m}} \alpha_{\mathrm{i}} \mathrm{a}_{\mathrm{t}-\mathrm{i}}^{2}+\sum_{\mathrm{j}=1}^{\mathrm{s}} \beta_{\mathrm{j}} \sigma_{\mathrm{t}-\mathrm{j}}^{2}
$$

where $\left\{\varepsilon_{\mathrm{t}}\right\}$ is an independent identically distributed random variable sequence with mean 0 and variance $1, \alpha_{0}>0, \alpha_{i} \geq 0, \beta_{j} \geq 0, \sum_{i=1}^{\max (m, s)}\left(\alpha_{\mathrm{i}}+\beta_{i}\right)<1$ (where $\mathrm{i}>\mathrm{m}, \alpha_{\mathrm{i}}=0$, for $\mathrm{j}>\mathrm{s}, \beta_{j}=$ $0)$.

According to the previous analysis results, we can use the ARMA $(7,5)$ model to fit the daily rate of return of the city investment. Therefore, when we make the GARCH model, we use model $\operatorname{ARMA}(7,5)$ above as the mean model. We selected the widely used GARCH $(1,1)$ model, the output of the model is as follows: 
Table 2 The result of $\operatorname{GARCH}(1,1)$

\begin{tabular}{ccccc}
\hline \hline \multicolumn{5}{c}{ Variance Equation } \\
\hline $\mathrm{c}$ & $1.14 \mathrm{E}-05$ & $5.55 \mathrm{E}-07$ & 20.52122 & 0.0000 \\
$\mathrm{RESID}(-1)^{\wedge} 2$ & 0.064783 & 0.003331 & 19.44739 & 0.0000 \\
GARCH $(-1)$ & 0.918038 & 0.003153 & 291.2094 & 0.0000 \\
\hline \hline
\end{tabular}

From the above table 6, we can see that the estimation coefficients of each parameter are significant, which shows that the GARCH model can fit the sample sequence well. We perform the LM test on the residuals of the model GARCH $(1,1)$.In the case of lagged order of 14, the F-statistic is not significant and the model effectively eliminates the correlation of time series, indicating that there is no ARCH effect. The model has a good explanation for the sample sequence. The coefficient of the stock's yield series is greater than zero, indicating that external shocks will exacerbate volatility in stock returns. While it is more than 0 less than 1 , indicating that the stock rate of return fluctuations have a certain memory [9]. The sum of the coefficients of the stock return series ARCH and GARCH is less than 1 (ie $0.064783+0.918038=0.982821$ ), indicating that the impact of the conditional heteroskedasticity is persistent, that is, the impact plays an important role in all future predictions [10].

The above GARCH model estimates that there is a symmetry in the stock market, but in reality the impact of the stock market is often asymmetric [11]. The stock is subject to negative impact is more likely to produce volatility, that is, the stock market there is a "leverage effect." In this paper, the TARCH $(1,1)$ model is established to study the asymmetric effect of the stock. The model estimates are as follows:

Table 3 The estimate of TARCH model

\begin{tabular}{crrrr}
\hline \hline \multicolumn{5}{c}{ Variance Equation } \\
\hline $\mathrm{C}$ & $9.34 \mathrm{E}-06$ & $4.23 \mathrm{E}-07$ & 22.07644 & 0.0000 \\
$\operatorname{RESID}(-1)^{\wedge} 2$ & $6.90 \mathrm{E}-02$ & $4.73 \mathrm{E}-03$ & 14.59509 & 0.0000 \\
$\operatorname{RESID}(-1)^{\wedge} 2^{*}(\mathrm{RESID}(-1)<0)$ & -0.028283 & 0.007032 & -4.021723 & 0.0001 \\
GARCH $(-1)$ & 0.930008 & 0.002457 & 378.4637 & 0.0000 \\
\hline \hline
\end{tabular}

From the test results, the residual sequence has no longer exist sequence correlation and ARCH effect, the model estimation results are valid. From the above table we can see that the estimation coefficients of each parameter are significant, indicating that the TARCH model can well fit the sample sequence. And the coefficient before the dummy variable is less than zero (-0.028283), indicating that the volatility of the stock yield does not have obvious leverage effect, but its coefficient is not equal to zero, indicating that although there is no leverage, but there is asymmetric effect, The amount of bad news and good news of the fluctuations are not the same.

\section{The Forecast of the Model}

Based on the ARMA-GARCH model, the stock rate of return of the joint simulation, the use of $\mathrm{R}$ software on the model of the stock yields are predicted as follows:

Table 4 The forecast of the model

\begin{tabular}{|l|l|l|l|l|l|}
\hline & 1 & 2 & 3 & 4 & 5 \\
\hline Rate of return & 0.00129581 & 0.00083417 & 0.00120013 & 0.00088651 & 0.00108326 \\
\hline Se error & 0.02708171 & 0.02716423 & 0.02717943 & 0.02718033 & 0.02718591 \\
\hline
\end{tabular}

It can be seen from the table that the effect of the model prediction is very good, the error is relatively small, we can see that the error is gradually increasing, because the multi-step prediction is the previous few steps to replace the actual value of the forecast, so the error will With the 
increase in the number of steps predicted, the accuracy will be reduced.

\section{Conclusions and Recommendations}

In this paper, the time series of Chengtou Holdings are modeled and analyzed. Through EViews software, an initial ARMA model is established for the data, and the advantages and disadvantages of each order are compared. Finally, the ARMA model is determined. While the ARCH effect is found in the residual test. Therefore, the final model is combined with the ARMA model and the GARCH model, and the two are combined to estimate. In conclusion, the ARMA model has a better ability to predict short-term prices. The ARCH model can eliminate the conditional heteroscedasticity for stock and other volatility data. The combination of the two can make the model more realistic and provide investors with better reference. Through the study of the cast shares of Chengtou Holdings, we draw the following conclusions:

- The fluctuation of the simple yield of the stock is aggregated and persistent, showing a certain degree of autocorrelation, partial self - correlation and heteroskedasticity.

- The volatility of stock return of China's listed real estate company has accumulated effect and memory effect. The GARCH coefficients in the model are both positive and statistically significant, indicating that the yield to maturity is continuous, that is, the current rate of return is subject to the impact of the past, and the larger volatility is often followed by a longer duration of fluctuation

- The GARCH model is a good measure of the volatility of stock returns. The TGARCH model is a good way to describe the asymmetric phenomenon of shocks in the stock market, that is, the response of investors to the same amount of bad news and good news is different. The establishment of the stock market in line with the operation of the law.

\section{References}

[1] Ruey S, Tsay. Introduction to financial data analysis [M]. Machinery Industry Press, 2013.

[2] Li Min. Shanghai stock market yield and volatility of the relationship between the study [J]. Shopping modernization, 2011, (01): 200.

[3] Feng Yuanyuan, Wang Xicheng, Feng Desai, Hu Bin. Corporate Social Responsibility Behavior and Equity Capital Costs - An Empirical Study Based on Chinese Listed Companies [J]. Friends of Accounting, 2016, (12): 46-52 The

[4] Yi Danhui. Data Analysis and EVIEWS Application. second edition. Beijing: Renmin University of China Press, 2008.

[5] ARMA model in China's sports stock price forecast application [J]. Fu Yan, Li Feng. Statistics and decision-making. 2012 (21)

[6] Based on the ARMA model of China's agricultural product price analysis and early warning [J]. Luo Yongheng. Economic Mathematics. 2013 (01)

[7] Xue Yi. Statistical Modeling and R Software [M]. Tsinghua University Press, 2014.

[8] Wang Wenhan.Using GARCH model to analyze the fluctuation rate of stock return rate of Huaxia Bank [J]. Modern Economic Information, 2015, (12): 294.

[9] Yu Jun, Jiang Wei, Long Qionghua.Study on long memory of international stock market yield and volatility [J]. Finance and Trade Research, 2007, (05): 84-90.

[10]. Journal of Huaihai Institute of Technology (Natural Science Edition), 2010, (01): 63-66. [J]. Journal of Huaihai Institute of Technology (Natural Science Edition), 2010, (01): 63-66.

[11] Feng Dawu. Research on Volatility of Chinese Stock Market Based on GARCH Model with Double Exponential Jump Factor, China Securities and Futures, 2012: 23-26. 